Check for updates

Cite this: RSC Adv., 2017, 7, 56704

\title{
Surface modification of electrospun nanofibrous membranes for oily wastewater separation
}

\author{
Fatma Yalcinkaya, (D) *a Anna Siekierka ${ }^{\mathrm{b}}$ and Marek Bryjak ${ }^{\mathrm{b}}$ \\ This paper presents a method for producing nanofibrous composite membranes for the separation of \\ a vegetable oil-water mixture. Neat polyvinylidene fluoride (PVDF), polyacrylonitrile (PAN) nanofibres and \\ PVDF/PAN mixtures were used to prepare the membranes. Argon plasma treatment, followed by \\ a chemical surface modification, was applied to alter the hydrophilicity and oleophobicity of the \\ membranes. The obtained results showed that the membranes change their surface character \\ (hydrophilicity and oleophilicity) in relation to the mixing ratio of the PVDF/PAN nanofibres and the \\ surface modification parameters. These results can extend the application of PVDF, PAN and PVDF/PAN \\ nanofibrous membranes to the treatment of oily water.
}

Received 29th October 2017

Accepted 8th December 2017

DOI: $10.1039 / c 7 r a 11904 f$

rsc.li/rsc-advances

outstanding chemical, thermal and oxidation resistance

\section{Introduction}

Oil-water emulsions emitted into the soil or water from domestic and industrial wastewater are one of the most severe issues that threaten human life and ecological systems, with a significant amount of oily wastewater generated every day. Thus, there is a growing demand to produce an oil-water separation system that has high selectivity, high efficiency, low fouling properties and is easy to apply and manage.

Microfiltration membranes are applied for oil-water separation treatment, along with other methods, such as bioremediation and chemical methods. ${ }^{1-3}$ The production of highperformance membranes with anti-fouling properties still remains challenging. Surface absorption, surface grafting and blending are some of the methods used for the surface modification of membranes ${ }^{4-10}$ to improve their anti-fouling properties. A hydrophilic membrane surface helps to reduce biofouling and protein adhesion in microfiltration. Blending materials is considered the simplest and most inexpensive approach for surface modification. Recently, the plasma modification method has attracted interest due to its extremely short modification time and non-destructive action. However, the modification is usually not permanent on most polymer surfaces, often disappearing within hours or days of treatment. ${ }^{11-13}$ To counteract this phenomenon, a post-treatment method should be applied to provide a permanent surface modification.

Polyvinylidene fluoride (PVDF) is one of the most frequently used polymers in membrane technology due to its

${ }^{a}$ Technical University of Liberec, Institute for Nanomaterials, Advanced Technology and Innovation, Studentska 1402/2, 46117 Liberec, Czech Republic. E-mail: yenertex@hotmail.com

${ }^{b}$ Wroclaw University of Science and Technology, Faculty of Chemistry, 27 Wybrzeze Stanislawa, Wyspianskiego, 50-370 Wroclaw, Poland properties, ${ }^{14-16}$ while polyacrylonitrile (PAN) is a common polymer that is characterised by its thermal stability, tolerance to most solvents, strong antioxidant capacity and commercial availability. ${ }^{17,18}$ PVDF has better mechanical properties than PAN. ${ }^{19}$ PAN is a hydrophilic polymer, whereas PVDF is a hydrophobic polymer. The versatility of both polymers thus makes them suitable for manufacturing membranes for liquid/liquid and liquid/solid separations.

The objective of this paper is to evaluate the properties of modified nanofibrous composite membranes obtained from PVDF, PAN and PVDF/PAN mixtures. Mixing the polymers should increase the hydrophilicity of the nanofibre web while also increasing the strength of the web by binding its fibres together. However, the main disadvantage regarding the use of nanofibres in filtration is their lack of mechanical integrity. Two of the novelties of this paper are that the nanofibre layers were produced with the Nanospider industrial equipment, ${ }^{20}$ and that the layers strongly adhered to a nonwoven supporting layer without any damage, using hot-press lamination technology to improve their performance in liquid filtration applications. The microwave plasma technique, followed by a chemical post-treatment, was used to hydrophilise the membrane surfaces. While similar papers dealing with the plasma modification of polymer membranes have been published, ${ }^{21-26}$ none have considered the use of a nanofibre web surface modification with both plasma and chemical treatments for liquid/liquid and liquid/solid separations. This study may thus provide a better understanding of the effects of surface modifications on the permeability and liquid selectivity of the membranes as a function of chemical modification time. 


\section{Materials and methods}

PAN (Elmarco s.r.o., Czech Republic) was dissolved in dimethylformamide (DMF) to produce an 8\% wt. PAN solution, and PVDF (Solef 1015, Belgium) was dissolved in dimethylacetamide (DMAc) to produce a $13 \%$ wt. PVDF solution. The DMF and DMAc solvents were purchased from Penta s.r.o., Czech Republic. The solutions were stirred overnight. Five different samples were prepared, defined by their PVDF/PAN nanofibre blend ratios (Table 1). A Nanospider electrospinning device (Elmarco s.r.o., Czech Republic) was used to produce the nanofibres under controlled and stable processing conditions, following previous studies (Fig. 1). ${ }^{27} \mathrm{~A}$ solution carriage feeds the polymer solution on a $0.2 \mathrm{~mm}$ moving stainless steel wire. The speed of the carriage is $245 \mathrm{~mm} \mathrm{~s}^{-1}$. High voltage suppliers are connected to the wire electrode $(60 \mathrm{kV})$ and the collector electrode $(-15 \mathrm{kV})$. When the applied voltage exceeds a critical value, the polymer solution jets move towards the collector, the solvent evaporates, and the nanofibre web is collected on baking paper moving in front of the collector electrode. The speed of the movement of the baking paper is $10 \mathrm{~cm} \mathrm{~min}^{-1}$. The distance between the electrodes is $18 \mathrm{~cm}$. The temperature and humidity of input air are set to $23{ }^{\circ} \mathrm{C}$ and $20 \%$ by the airconditioning system. The intake and outlet airflows are 100 and $115 \mathrm{~m}^{3} \mathrm{~h}^{-1}$, respectively.

The zero-shear viscosity of the polymer solutions was measured using a Fungilab Expert viscometer at $23{ }^{\circ} \mathrm{C}$.

Pressure-driven liquid filtration applications require that the membranes possess sufficient mechanical strength to withstand the operational conditions. The nanofibres were thus laminated onto a nonwoven spunbond supporting material to improve the mechanical strength of the membranes. The surface of the membranes was characterised by Scanning Electron Microscope (SEM, Vega 3SB) and the fibre diameters were analysed using the Image-J image processing software. The surface contact angle of the samples was measured at room temperature using a Kruss Drop Shape Analyzer DS4 with distilled water on the clean and dry samples. The PVDF/PAN mixture of polymeric nanofibres was evaluated using Fourier transform infrared spectroscopy (FTIR, Nicolet iZ10 by Thermo Scientific). A 1200-AEL capillary flow porometer (Porous Media Inc., Ithaca, NY) was used in this study to measure the pore size of the samples.

The prepared nanofibrous composite membranes were cut into $5 \mathrm{~cm} \times 5 \mathrm{~cm}$ squares and subjected to the standard plasma treatment. ${ }^{10}$ Microwave-induced low vacuum argon (Ar) plasma

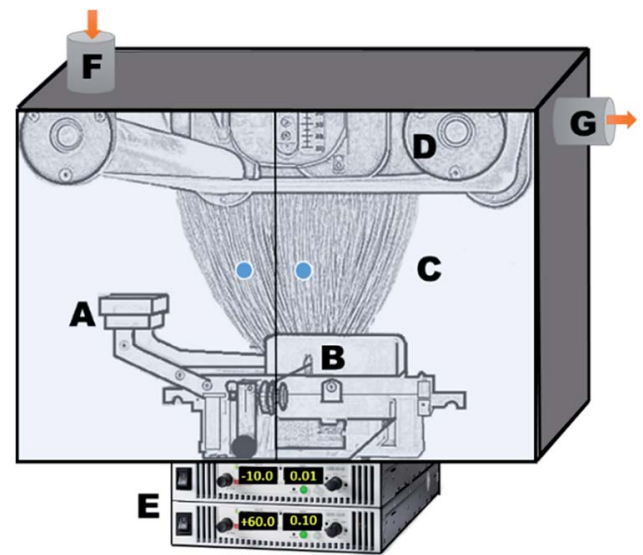

Fig. 1 Schematic illustration of the electrospinning device, with key components labelled. (A) Solution tank (feeds the solution towards the wire); (B) wire electrode; (C) spinning area; (D) collecting electrode, connected to a silicon paper as supporting material; (E) high voltage supply; (F) air intake; and (G) air outlet.

was used to modify the surface for $5 \mathrm{~min}$. The scheme of the plasma reactor is shown in Fig. 2. After the plasma treatment, the samples were exposed to the atmosphere for $20 \mathrm{~min}$ and then immersed in $1 \mathrm{M}$ sodium hydroxide $(\mathrm{NaOH})$ aqueous solution. The times of sample immersion were $0,2,4,6$ and $24 \mathrm{~h}$. The samples were then rinsed and kept in distilled water.

A Millipore Amicon $50 \mathrm{~mL}$ stirred filtration cell (Millipore Corporation Billerica, Massachusetts, USA), with an active filtration area of $13.4 \mathrm{~cm}^{2}$, was used to evaluate membrane

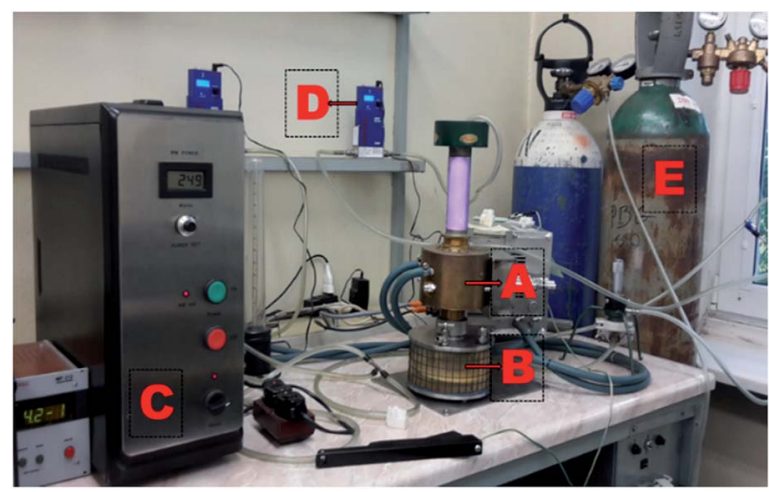

Fig. 2 Remote microwave plasma device, with key components labelled. (A) Low vacuum microwave plasma head; (B) reaction chamber; (C) MW generator; (D) Ar gas flowmeter; and (E) Ar gas tank.

Table 1 Key physical parameters of the PVDF/FAN samples analysed in this study

\begin{tabular}{llllr}
\hline Sample code & PVDF/PAN wt ratio & Viscosity $(\mathrm{mPa})$ & Area weight $\left(\mathrm{g} \mathrm{m}^{-2}\right)$ & Pore size $(\mathrm{nm})$ \\
\hline S1 & $1 / 0$ & 969.3 & $3.52 \pm 0.5$ & $2030 \pm 562$ \\
S2 & $0 / 1$ & 190.9 & $1.29 \pm 0.5$ & $710 \pm 344$ \\
S3 & $2 / 1$ & 718.0 & $1.99 \pm 0.5$ & $790 \pm 516$ \\
S4 & $1 / 1$ & 499.3 & $4.35 \pm 0.5$ & $910 \pm 245$ \\
S5 & $1 / 2$ & 348.5 & $0.72 \pm 0.5$ & $820 \pm 324$
\end{tabular}




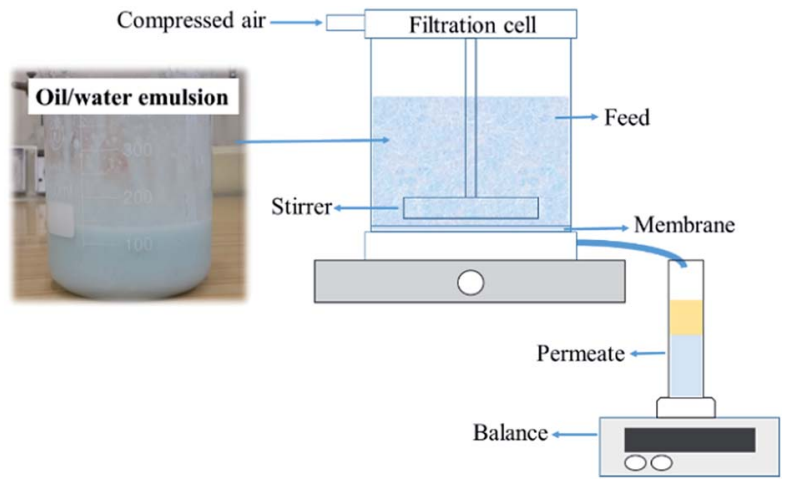

Fig. 3 Schematic diagram of dead-end filtration.

performance (Fig. 3). The feed solution was prepared by mixing blue-coloured distilled water with vegetable (kitchen) oil in a $1: 1$ volume ratio. Water was coloured using methylene blue to properly observe the separation process. The feed solution was mixed with a hand mixer for a few minutes until a uniform mixture was obtained. The tested dry membrane was placed in the filtration cell, which was then filled with $20 \mathrm{~mL}$ of filtrated distilled water. The separation conditions were created under 0.02 bar pressure. A $50 \mathrm{~mL}$ oil-water mixture was used for each test. The oil-water mixture did not separate into two phases during filtration. A magnetic stirrer was used to mix the feed solution during filtration. After the separation test, the permeate solution was collected in a glass graduated cylinder tube and sealed tightly to avoid evaporation. The permeate was kept for $24 \mathrm{~h}$ to separate into two phases and then determine the resultant water and oil percentages in volume ratio. The oil and water contents were calculated according to eqn (1):

$$
C_{\mathrm{S}}=\frac{V_{\mathrm{S}}}{V_{\mathrm{P}}} \times 100 \%,
$$

where $C_{\mathrm{S}}$ is the content of selected liquid (oil or water), $V_{\mathrm{S}}$ is the volume of selected liquid and $V_{\mathrm{P}}$ is the total volume of the permeate.

The permeate flux $(F)$ and permeability $(k)$ of the membrane were calculated according to eqn (2) and (3), respectively:

$$
\begin{gathered}
F=\frac{1}{A} \frac{\mathrm{d} V}{\mathrm{~d} t}, \\
k=\frac{F}{p},
\end{gathered}
$$

where $A$ is the effective membrane area $\left(\mathrm{m}^{2}\right), V$ is the total volume of $F, p$ is transmembrane pressure (bar) and $t$ is the filtration time.

\section{Results and discussion}

\subsection{Surface analysis and characterisation of the unmodified membranes}

The SEM images in Fig. 4 show that there is no damage to the fibres on the top surface of the substrate, which suggests that the lamination was done successfully.
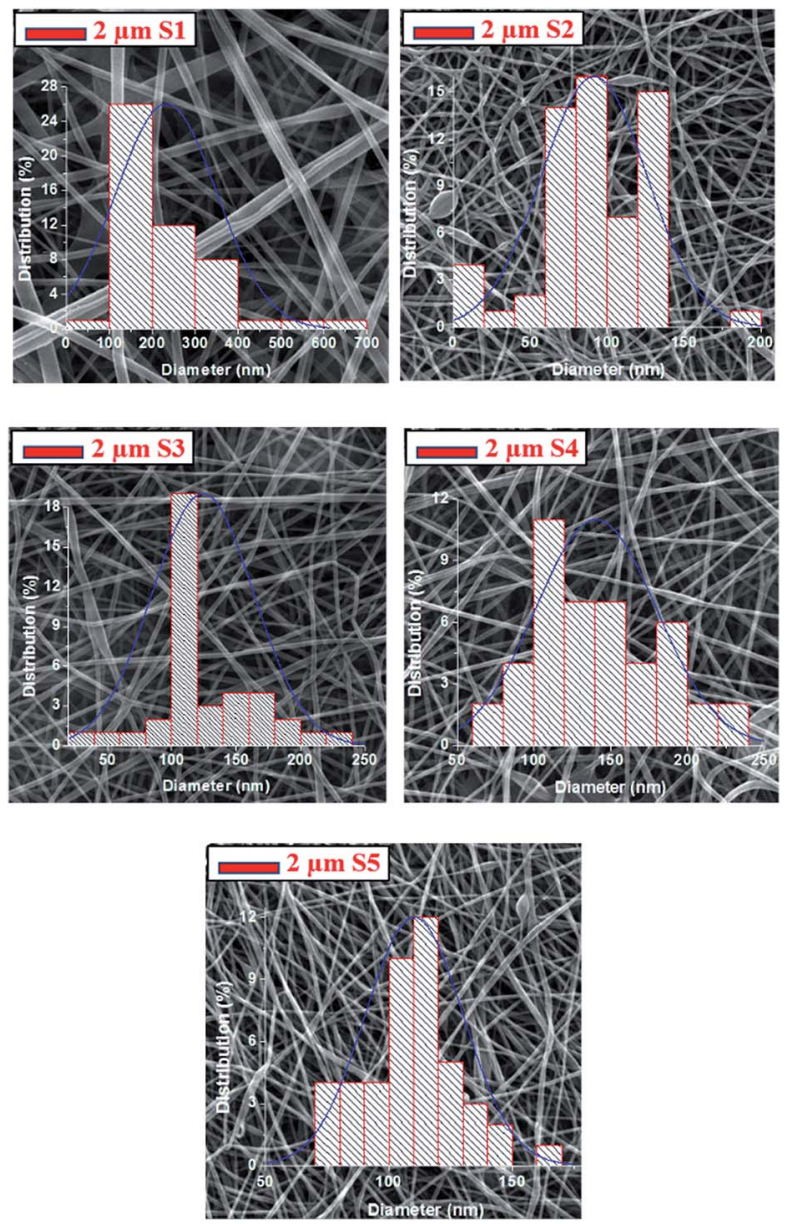

Fig. 4 SEM images of the unmodified samples after lamination.

It should be noted that the PVDF nanofibres possess a fibre diameter that is $\sim 2.5$ times larger than that of the PAN nanofibres. Mixing the PVDF polymer with PAN yields a fibre diameter that is $\sim 1.6$ times smaller than that of the neat PVDF sample nanofibres. It was observed that the neat PAN nanofibres have a beaded structure, which could be due to the low viscosity of the PAN solution (Table 1). Bead-free nanofibres were obtained after mixing PAN with PVDF. There were no visible changes in the observed fibre diameter after lamination.

Water contact angle measurements are one of the simplest and easiest methods for determining the hydrophilic or hydrophobic nature of chemical groups attached to the surface of the layers. Based on the water contact angle observations (Fig. 5), it was evident that the addition of PAN increased the hydrophilicity of the resultant PVDF/PAN membranes. The results showed that a neat PAN (S2) web, with a contact angle of less than $90^{\circ}$, could be considered as a hydrophilic material. ${ }^{28}$ Sample S5 had a contact angle close to $90^{\circ}$, while samples S1, S3 and $\mathrm{S} 4$ each had angles larger than $90^{\circ}$ and exhibited hydrophobic characteristics. The contact angles changed after surface modification. The plasma and chemical modifications resulted in fully wettable surfaces with a contact angle of $0^{\circ}$. Only two modified images are shown in Fig. 5. Tran et al. ${ }^{29}$ found that using non-polymer-forming plasma gas treatments, such as Ar, 

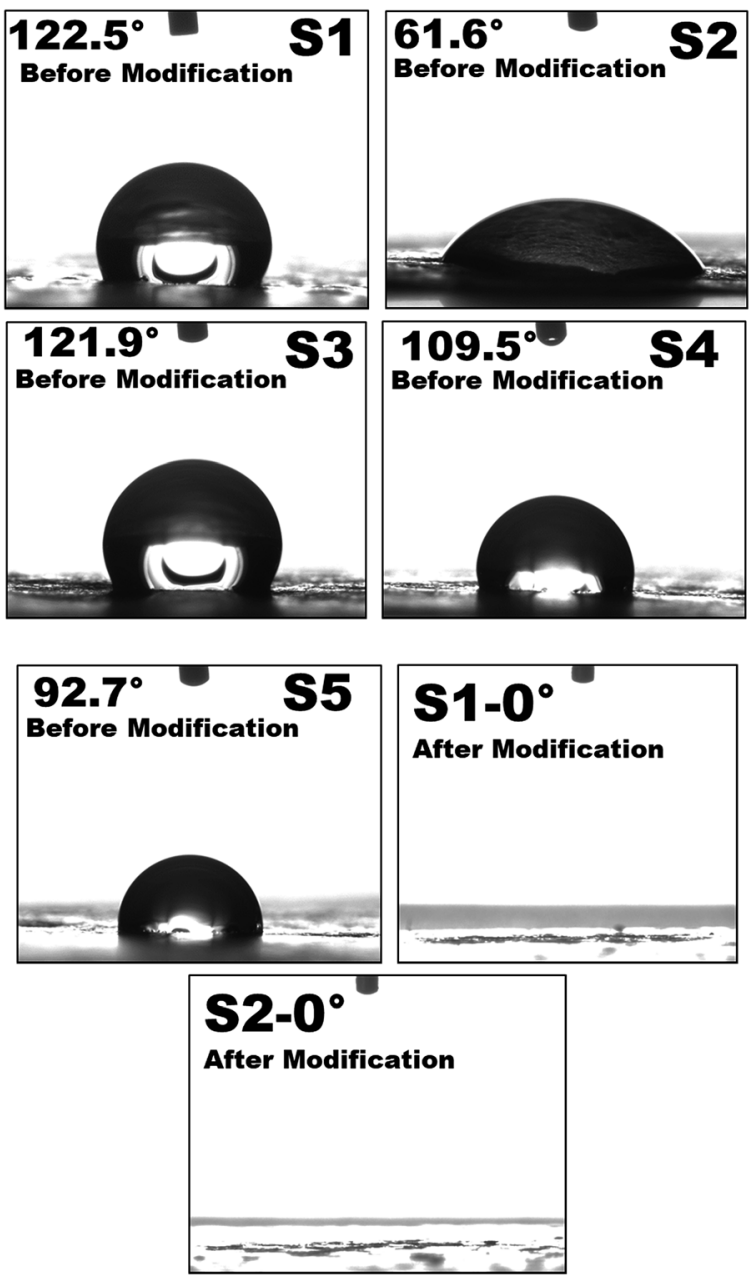

Fig. 5 Water contact angles of unmodified and modified nanofibrous membranes.

$\mathrm{He}$ and $\mathrm{O}_{2}$ plasma treatments, increase the membrane surface hydrophilicity and membrane permeability. Similarly, superhydrophilic PVDF electrospun membranes have been obtained by oxygen plasma treatment. Moreover, the plasma treatment did not significantly influence the average size and morphology of the nanofibres. ${ }^{30}$ Another study showed that both the surface modifications of PVDF and the surface wettability improved under plasma exposure. ${ }^{31}$ The most significant result is the hydrophilic modification of the PVDF membrane.

The FTIR spectra were collected to investigate the chemical structure of the PVDF/PAN nanofibrous webs, shown in Fig. 6. The spectra confirmed the presence of both polymers in the blends, the absorption bands at $2240 \mathrm{~cm}^{-1}$ and $1664 \mathrm{~cm}^{-1}$ for the PAN nitrile groups and the stretching bands at $1173 \mathrm{~cm}^{-1}$ and $876 \mathrm{~cm}^{-1}$ for the $-\mathrm{CF}_{2}$ and $\mathrm{C}-\mathrm{F}$ groups of PVDF, respectively. The characteristic peaks for PVDF and PAN were modified according to the composition of the PVDF/PAN mixture.

\subsection{Characterisation of the modified membranes}

The mechanism of plasma deposition and chemical surface modification is shown in Fig. 7. Ar plasma treatment and

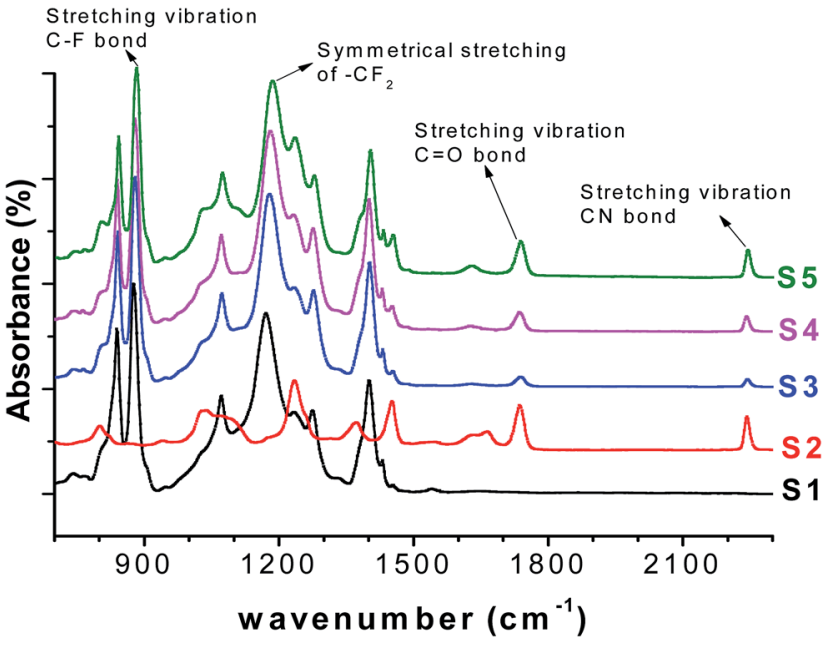

Fig. 6 FTIR spectra of the five PVDF/PAN samples.

chemical operation with $\mathrm{NaOH}$ were used to modify the membrane surfaces. The Ar plasma treatment should crosslink the polymers on the surface fibres and introduce polar groups there, while the chemical operation with $\mathrm{NaOH}$ should turn the nitrile groups into more polar carboxylic functionalities. The exploitation of both methods of surface modification should provide more stable and highly hydrophilic properties for the long-lasting service of the membranes.

FTIR spectra were used to verify the effect of the plasma and chemical modifications on the composite membrane surfaces of S1, S2 and S4 (Fig. 8-10). Fig. 8-10 show that the modification caused a marked change in the surface functionality for the PVDF membranes, while only slight changes were observed for the PAN and PVDF/PAN (1/1) membranes. Tables 2 and 3 describe the key absorbance peaks of the evaluated membranes in greater detail.

Compared to unmodified PAN membranes, the peak at $1737 \mathrm{~cm}^{-1}$ shifted to $1733 \mathrm{~cm}^{-1}$ after surface modification (Fig. 8). A sharp increase in the peak at $1733 \mathrm{~cm}^{-1}$ was observed after the plasma treatment and $\mathrm{NaOH}$ surface modification, likely due to the presence of an extra carboxylic group on the modified surface.

Significant differences were observed after surface modification of the PVDF membranes (Fig. 9). The very broad and less intense peak between 2500 and $3500 \mathrm{~cm}^{-1}$ was due to $\mathrm{O}-\mathrm{H}$ functionalities that improve the hydrophilicity of the membranes. The change in peak shape was due to of the extent of hydrogen bond stretching among the alcohol or carboxylic acid groups. These peaks change significantly with the surface

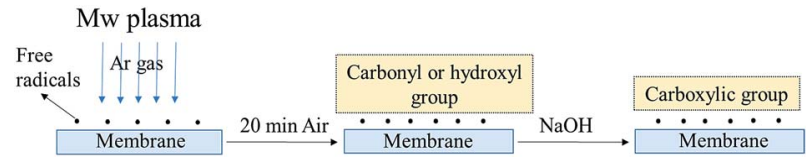

Fig. 7 Schematic diagram of membrane surface modification using a plasma and $\mathrm{NaOH}$ solution. 


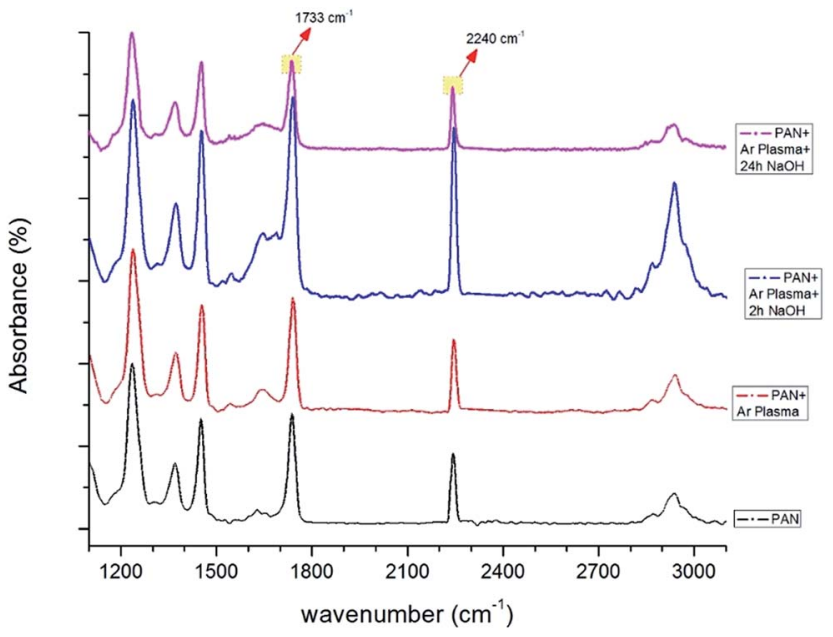

Fig. 8 FTIR spectra of PAN membranes before and after surface treatment (only Ar plasma, Ar plasma $+2 \mathrm{~h} \mathrm{NaOH}, \mathrm{Ar}$ plasma $+24 \mathrm{~h}$ $\mathrm{NaOH})$.

modification and length of $\mathrm{NaOH}$ treatment. The peak at $2928 \mathrm{~cm}^{-1}$ indicated the $\mathrm{C}-\mathrm{H}$ stretching frequency due to the parent hydrocarbon chain of the compound.

There were no significant changes in the PVDF/PAN 1/1 mixture after surface modification (Fig. 10). The FTIR results indicate that the surface of the PVDF membrane was successfully modified, following the modification mechanism shown in Fig. 7. Given the presence of carboxylic groups on the membrane surface, one can expect the highly permeable and anti-fouling reaction of such materials.

\subsection{Oil-water separation}

Surface treatment allows for the creation of specific surface chemistries that increase membrane permeability and reduce membrane fouling. However, separation of the oil-water mixture is always difficult, so several microfilters are used for this purpose.

The filtration results for the unmodified membranes, as well as the membranes modified by the Ar plasma and $\mathrm{NaOH}$ treatments, are shown in Fig. 11. The permeability of the membranes was compared before and after surface modification. The time " 0 " refers to the membranes without any treatment. The distilled water permeability values increased tremendously for the modified membranes.

The permeability of all of the composite membranes depends on both the surface modification and modification time. It was found that the immersion of the samples in $\mathrm{NaOH}$ for $6 \mathrm{~h}$ resulted in the highest permeability result for each membrane type (Fig. 11). The highest permeability was achieved for the S5 sample, which was 20 times higher than the permeability of the untreated S5 sample.

It was observed that the permeabilities of S2, S4 and S5 decreased after increasing the $\mathrm{NaOH}$ immersion to $24 \mathrm{~h}$ (Fig. 11). A commercially available ultrafiltration membrane of PAN was pre-treated in $\mathrm{NaOH}$ solution. ${ }^{47}$ The $\mathrm{NaOH}$-induced hydrolysis of nitrile groups on the membrane surface led to a decrease in both the pore diameter and permeability of the membrane. The average pore diameter underwent a 4.3 -fold decrease during the hydrolysis. The results showed that modification of the membrane surface by anchoring carboxylic groups made the surface less prone to protein deposition. The hydrolysis of PAN and PAN/PVDF membranes resulted in the

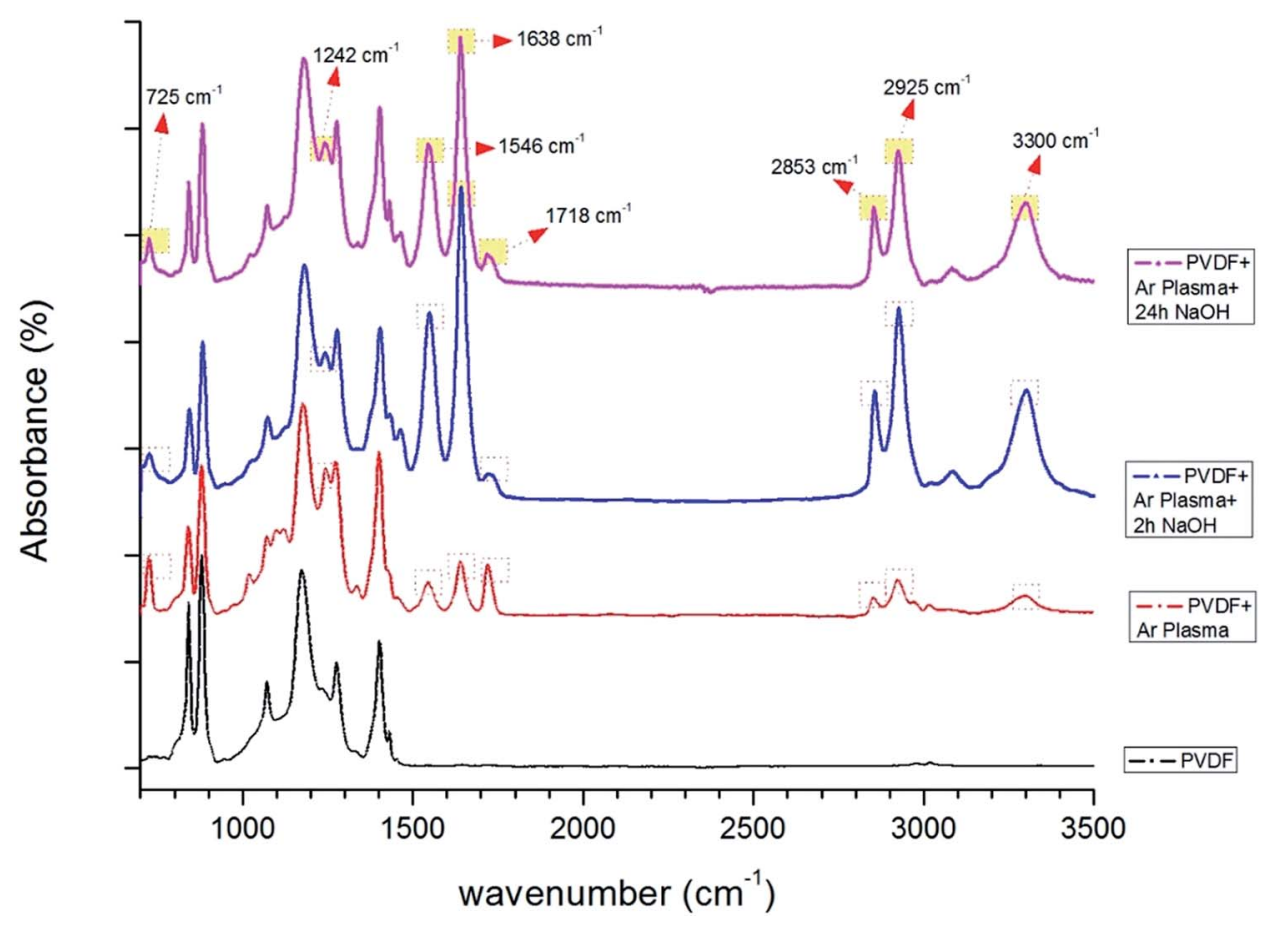

Fig. 9 FTIR spectra of PVDF membranes before and after surface treatment (only Ar plasma, Ar plasma $+2 \mathrm{~h} \mathrm{NaOH}, \mathrm{Ar}$ plasma $+24 \mathrm{~h} \mathrm{NaOH}$ ). 


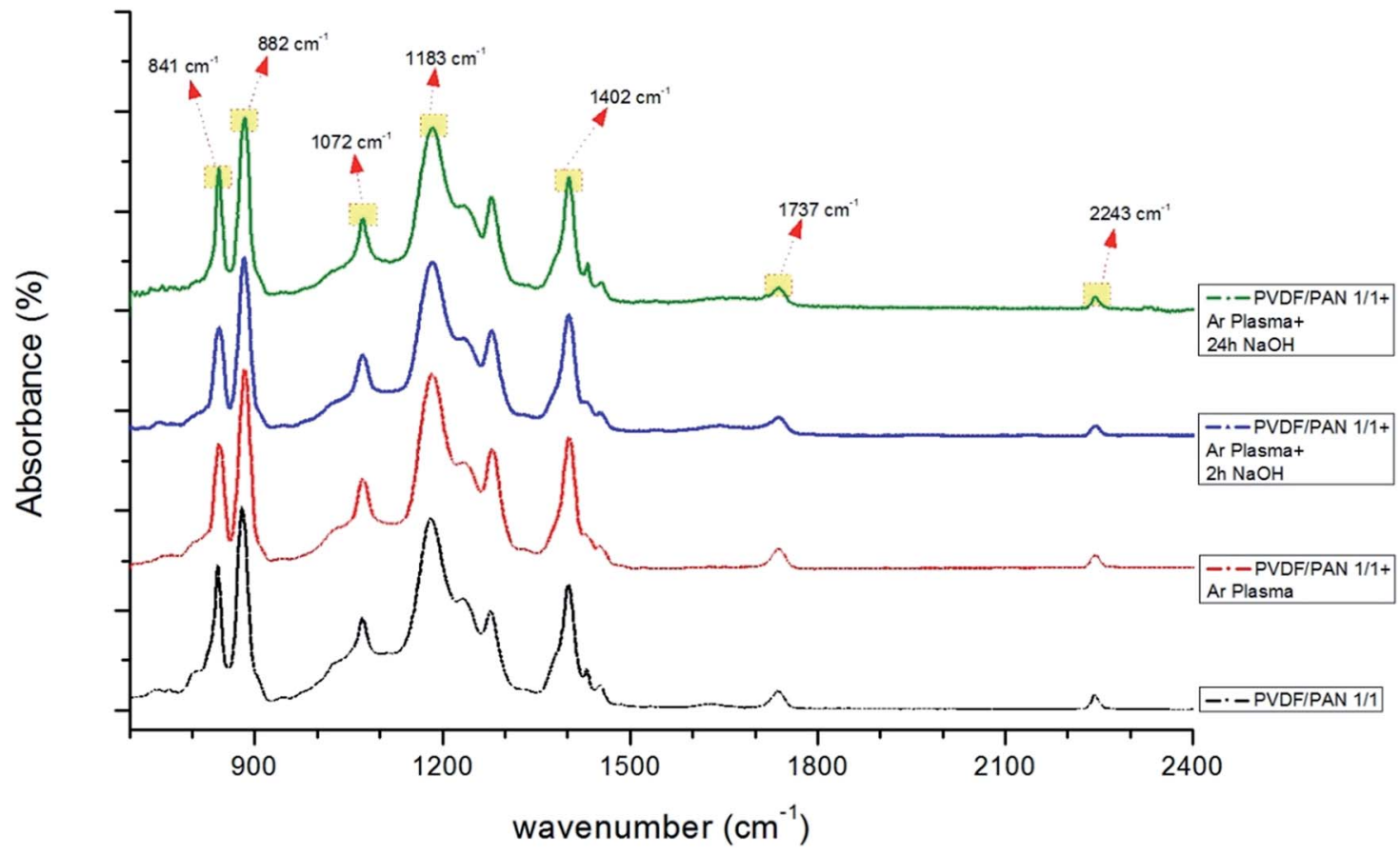

Fig. 10 FTIR spectra of PVDF/PAN (1/1) membranes before and after surface treatment (only Ar plasma, $\operatorname{Ar}$ plasma $+2 \mathrm{~h} \mathrm{NaOH}, \mathrm{Ar}$ plasma $+24 \mathrm{~h}$ $\mathrm{NaOH}$ ).

swelling of the PAN polymers and a decrease in pore diameter. The pore sizes of the membranes were not measured after surface modification. The swollen pores apparently reduced the permeability of the membranes. A $6 \mathrm{~h} \mathrm{NaOH}$ treatment seems optimum for all membranes.

An example filtration procedure for an oil-water mixture through the prepared membranes is shown in Fig. 12, with the results of the separation included in Table 4.

The results in Table 4 show that the modification of the nanofibrous membranes had a great effect on the selectivity of the membranes. The membranes in the first row, with a zero immersion time, had no surface treatment. Opposite to unmodified PAN, the unmodified PVDF shows hydrophobic/ oleophilic properties. Similar results were recorded in the literature, where the neat PVDF membranes showed hydrophobic/oleophilic characteristics either in surfactant-free

Table 2 FTIR spectroscopy absorption bands for modified and unmodified PAN

Wavelength $\left(\mathrm{cm}^{-1}\right) \quad$ Explanation

1240, 1369, 1453, Vibration of aliphatic $\mathrm{CH}$ groups

2938

1733,1737

2240,2242 $\left(\mathrm{CH}, \mathrm{CH}_{2}, \mathrm{CH}_{3}\right)^{32}$

Stretching vibration of the $\mathrm{C}=\mathrm{O}$ bond. The presence of this $\mathrm{C}=\mathrm{O}$ peak could be due to residual DMF in the PAN fibers. ${ }^{32}$ Moreover, additional surface treatment changes the intensity of the peak due to the carboxylic group on the surface (CN) in acrylonitrile structure ${ }^{33}$
Stretching vibration of the nitrile groups water-in-oil emulsion or a surfactant-stabilised water-in-oil emulsion. ${ }^{48-50}$ The hydrophilicity and oleophilicity of the unmodified membranes change based on the ratio of PVDF/ PAN. In the sample of PAN composite membranes, the hydrophilic/oleophobic characteristics of the PAN did not change after surface modification. However, the water permeability of the PAN composite membranes underwent a 4-fold improvement after $6 \mathrm{~h}$ of immersion in the $\mathrm{NaOH}$ solution. It was observed that surface modification of neat PVDF allowed the material to exhibit hydrophilic properties. The literature showed that treated PVDF membranes can convert the membrane from being highly hydrophobic to being superhydrophilic when wetted with water and with a high permeability. ${ }^{51,52}$ When the porous hydrophobic material is immersed in water, the water cannot penetrate the pores. However, the reduction of the surface tension of the solution (by the addition of salt or $\mathrm{NaOH}$ ) made the membranes 'permeable' for water. The effects of both the surface modification and the increase in pore permeability improve the membrane hydrophilicity. Zhang et $a l .{ }^{53}$ prepared a superhydrophilic/superoleophobic PAN ultrafiltration membrane by an alkaline-induced phase inversion process by the addition of $\mathrm{NaOH}$ into coagulation bath. This induced the in situ hydrolysis of - $\mathrm{CN}$ groups in the PAN chain to $-\mathrm{COOH}$ groups, which resulted in the superwetting of the PAN membranes. The membrane showed ultralow oil adhesion, thus endowing the membrane with superior oilwater separation properties and a high water permeability.

The mixture of polymers showed that it was possible to control the oil or water uptake by altering the time of modification. In general, it is possible to conclude that the surface modification of the membranes improves their hydrophilicity 
Table 3 FTIR spectroscopy absorption bands for modified and unmodified PVDF

\begin{tabular}{|c|c|}
\hline Wavelength $\left(\mathrm{cm}^{-1}\right)$ & Explanation \\
\hline 725 & $\begin{array}{l}\text { Methylene swing in-plane vibration } \\
\text { due to C-C rocking vibrations in }-\left(\mathrm{CH}_{2}\right)_{n} \text {. } \\
\text { The absorbance is originating from } \\
\text { exposure of the polymer + plasma bond } \\
\text { to air for } 20 \mathrm{~min}^{34,35}\end{array}$ \\
\hline 841 & $\mathrm{C}-\mathrm{F}$ stretching vibration of $\mathrm{PVDF}^{36}$ \\
\hline 881 & $\begin{array}{l}\mathrm{C}-\mathrm{C}-\mathrm{C} \text { asymmetrical stretching vibration } \\
\text { of } \mathrm{PVDF}^{36}\end{array}$ \\
\hline 1175 & $\begin{array}{l}\text { Band for }-\mathrm{CF}_{2} \text { symmetrical stretching and } \\
\alpha \text { phase of } \mathrm{PVDF}^{37-39}\end{array}$ \\
\hline 1242 & $\begin{array}{l}\text { Enhanced carbonyl absorption peak }-\mathrm{C}-\mathrm{O} \text { - } \\
\text { stretching band }{ }^{40,41}\end{array}$ \\
\hline 1401 & $-\mathrm{C}-\mathrm{F}-$ stretching $^{39}$ \\
\hline 1546 & Carboxylate peak asymmetric $-\mathrm{O}-\mathrm{C}-\mathrm{O}-{ }^{42}$ \\
\hline $1638-1718$ & $\begin{array}{l}\text { Carbonyl }(\mathrm{C}=\mathrm{O}) \text { stretching vibrations. } \\
\text { Primarily centred around } 1710-1720 \mathrm{~cm}^{-1} \\
\text { (ref. } 43 \text { ) }\end{array}$ \\
\hline 2853 & Symmetric stretching of $\mathrm{CH}_{2}$ \\
\hline 2925 & Asymmetric stretching of $\mathrm{C}-\mathrm{H}^{44}$ \\
\hline 3020 & $\begin{array}{l}\text { Asymmetric starching vibration of the } \\
\mathrm{CH}_{2} \text { groups }\end{array}$ \\
\hline $2500-3300$ & $\mathrm{O}-\mathrm{H}$ stretching absorption ${ }^{46}$ \\
\hline
\end{tabular}

while decreasing their oleophilicity. PVDF nanofibres had a better mechanical and abrasion resistance compared to the PAN nanofibres. Surface-modified PVDF nanofibres seem to be suitable for the separation of water from water-oil mixtures. Moreover, it was found that a mixture of PVDF with PAN can be hydrophilic/oleophobic and gain a higher permeability compared to neat PVDF and neat PAN membranes.

The study presents the first industrial nanofibre production method to fabricate nanofibres for the separation of oily wastewater. Moreover, easy spinnable polymers and an inexpensive surface modification method were used to change surface hydrophilicity and oleophobicity. Compared to similar

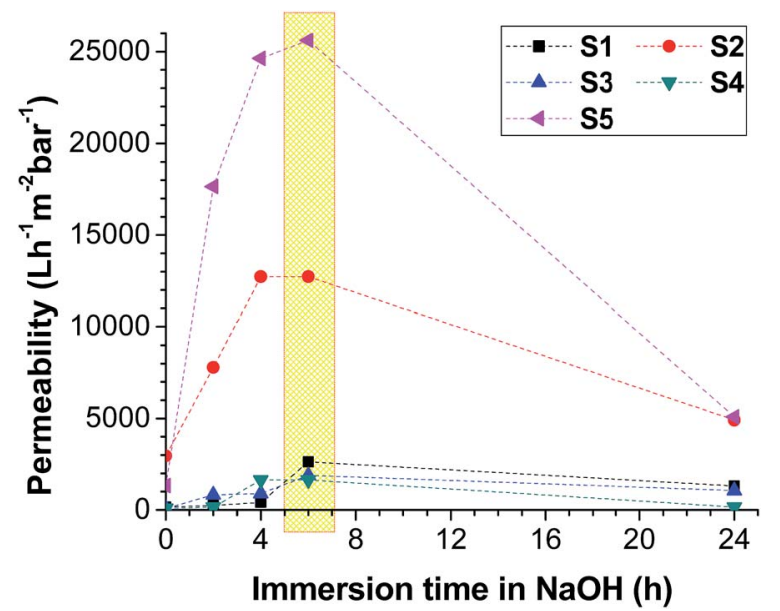

Fig. 11 The permeability of the samples after various modification times in the $\mathrm{NaOH}$ solution.

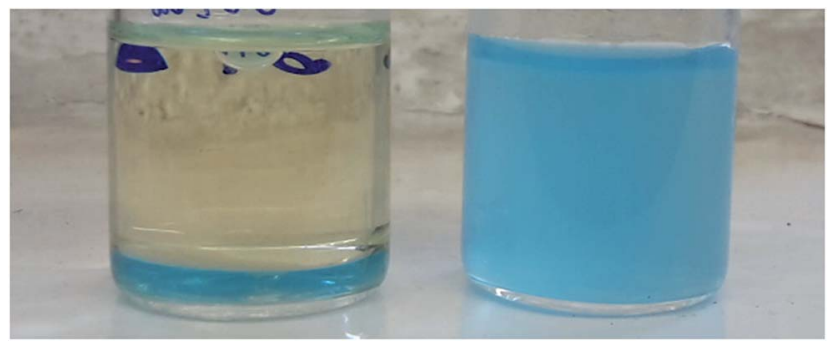

Fig. 12 Permeates after oil-water filtration. Sample S1 (left) and S2 (right) after $4 \mathrm{~h}$ in $\mathrm{NaOH}$ solution.

studies in the literature, the membranes tested here showed very high permeability after separation..$^{54-58}$

Based on the permeability and selectivity results, S5 was selected as the best candidate for the filtration of oily wastewater. The surface morphology of S5 was investigated by SEM image after surface modification and separation test, as shown in Fig. 13.

The SEM results showed that the diameter of the nanofibres increased with increasing immersion time, while the size distribution of the nanofibres improved. This is due to the swelling of PAN nanofibres in the $\mathrm{NaOH}$ aqueous solution. Similar results were obtained in the literature. ${ }^{47}$ Yang et al. ${ }^{59}$ found that after immersing the PAN membranes in $\mathrm{NaOH}$, the hydraulic permeability decreased, and an increase in the rejection of dextran was observed due to the swelling of the hydrolysed layer. Kim et al. ${ }^{60}$ found that the annealed PAN membrane underwent a decrease in pore size after it was treated with $2 \mathrm{M} \mathrm{NaOH}$ or $\mathrm{CH}_{3} \mathrm{ONa}$ for over $2 \mathrm{~h}$. The reason for this is that $\mathrm{NaOH}$-induced hydrolysis of the nitrile groups on the membrane surface results in membranes with decreasing pore diameters. The pore diameters of the samples were not measured after modification, because the pore size measurements were done on dry membranes. Drying the wet nanofibre web would cause cracking on the surface of the nanofibres, which highlights that it is better to keep the membrane in a wet condition once it has been wetted. After surface modification, the membranes were kept in distilled water until the separation test was run. The SEM results indicate that fibres grew and became flattened, likely due to the decrease in pore size. After separation, the membranes were dried in the oven without any cleaning, and the SEM images were taken. The images showed that after oil separation, all membrane surfaces were contaminated with oil (Fig. 13). The fibres are barely visible under a cake

Table 4 The water and oil contents in the permeates

\begin{tabular}{|c|c|c|c|c|c|c|c|c|c|c|}
\hline \multirow{2}{*}{$\begin{array}{l}\text { Time in } \mathrm{NaOH} \\
\text { (h) }\end{array}$} & \multicolumn{5}{|c|}{ Water content (\%) } & \multicolumn{5}{|c|}{ Oil content (\%) } \\
\hline & S1 & $\mathrm{S} 2$ & $\mathrm{~S} 3$ & S4 & S5 & S1 & $\mathrm{S} 2$ & $\mathrm{~S} 3$ & S4 & S5 \\
\hline 0 & 0 & 100 & 0 & 50 & 73 & 100 & 0 & 100 & 50 & 27 \\
\hline 2 & 10 & 100 & 26 & 100 & 81 & 90 & 0 & 74 & 0 & 19 \\
\hline 4 & 18 & 100 & 50 & 100 & 86 & 82 & 0 & 50 & 0 & 14 \\
\hline 6 & 74 & 100 & 100 & 100 & 100 & 26 & 0 & 0 & 0 & 0 \\
\hline 24 & 78 & 100 & 100 & 100 & 100 & 22 & 0 & 0 & 0 & 0 \\
\hline
\end{tabular}



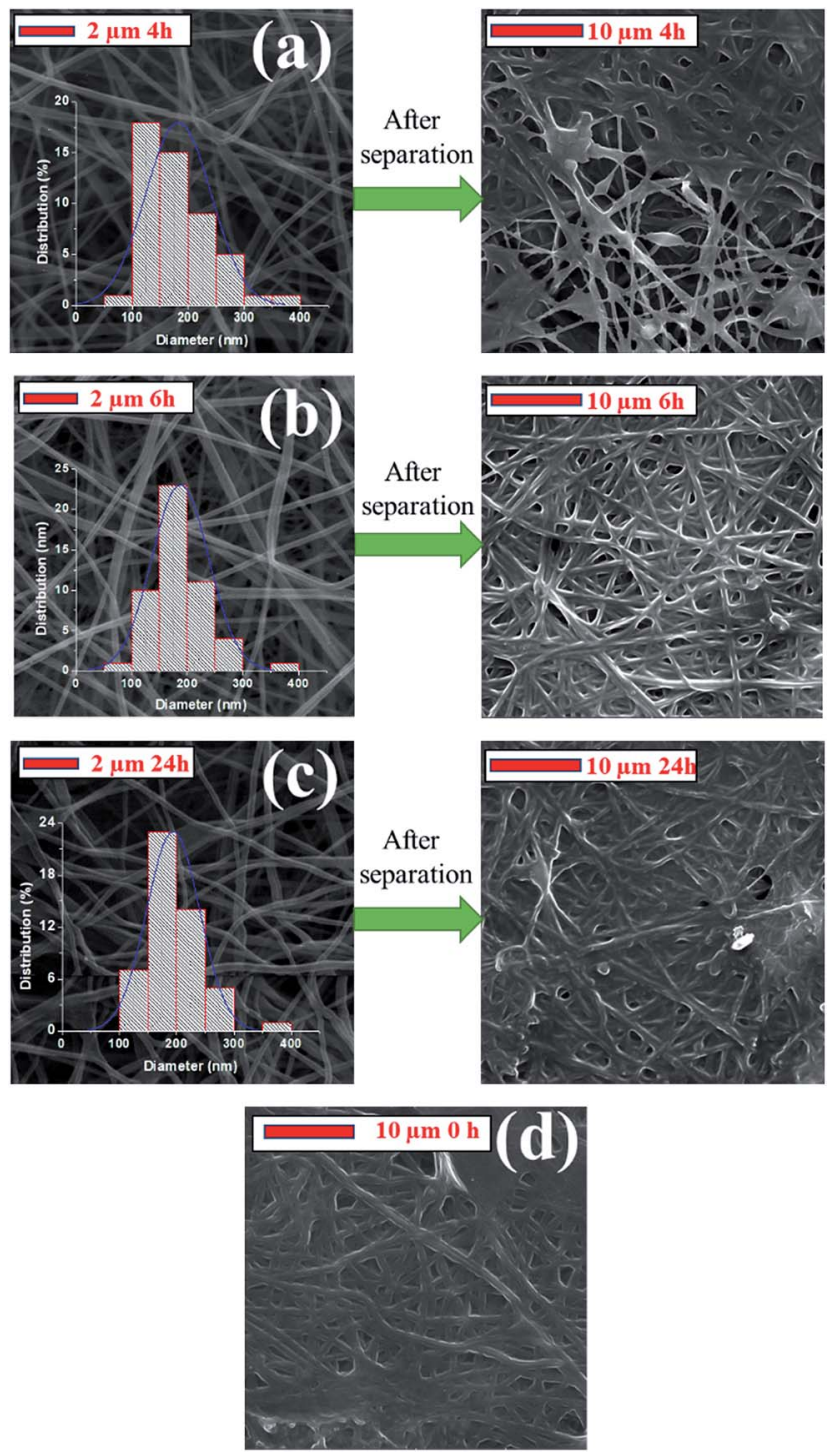

Fig. 13 SEM images of sample S5 after: (a) $4 \mathrm{~h}$, (b) $6 \mathrm{~h}$ and (c) $24 \mathrm{~h}$ surface modification and their SEM images after the separation test, (d) unmodified membrane after the separation test.

layer. The permeability results of the $24 \mathrm{~h}$ modification were quite low compared to the 2, 4 and $6 \mathrm{~h}$ separation tests. It is visible from the SEM image that the total surface of the $24 \mathrm{~h}$ modified membrane was totally covered with an oil film, which led to a marked decrease in its permeability.

\section{Conclusions}

Functional PVDF, PAN and PVDF/PAN nanofibrous composite membranes were successfully fabricated for the separation of an oily wastewater. It was found that both the polymer blending method and modification of the membranes can change the surface hydrophilicity and oleophilicity. These changes can be attributed to structural changes in the membranes to decrease surface energy and increase in pore permeability.
The membrane permeability can also be altered based on the chemical treatment parameters. In the case of membranes with modified PAN, water permeability increases dramatically. Depending on modification parameter, a permeability of $25000 \mathrm{~L} \mathrm{~m}^{-2} \mathrm{~h} \mathrm{bar}^{-1}$ was achieved with Ar plasma exposure followed by $\mathrm{NaOH}$ modification. The FTIR results confirm the polymer mixture and surface modification. Contact angle measurements showed that after surface treatment, membranes become highly hydrophilic, with the water drop immediately disappearing. SEM studies revealed no physical damage to the polymer surface lamination.

The distilled water flux for the modified membranes increased dramatically because of its high hydrophilicity. The oily wastewater fouling was considerably reduced by the membrane flux for modified membranes.

Improved strength and, in the instance of PVDF, the improved wettability of the membranes, make them more suitable for aqueous filtration. These prepared membranes could thus be used for the practical microfiltration of oily wastewater.

\section{Conflicts of interest}

There are no conflicts to declare.

\section{Acknowledgements}

This work was supported by the Ministry of Education, Youth and Sports of the Czech Republic in the framework of the targeted support of the "National Programme for Sustainability I" (project LO1201) and the Czech Republic Operational Programme Research and Development for Innovation (OPR \& DI; project CZ.1.05/2.1.00/19.0386). The authors would also like to thank Mrs Jana Mullerova for her help in the FTIR measurements.

\section{Notes and references}

1 M. A. Zahed, H. A. Aziz, M. H. Isa, L. Mohajeri and S. Mohajeri, Bioresour. Technol., 2010, 101, 9455-9460.

2 A. Vidyasagar, K. Handore and K. M. Sureshan, Angew. Chem., Int. Ed., 2011, 50, 8021-8024.

3 R. R. Fouad, H. A. Aljohani and K. R. Shoueir, Mar. Pollut. Bull., 2016, 112, 46-52.

4 J. Kim and B. Van der Bruggen, Environ. Pollut., 2010, 158, 2335-2349.

5 X. Zhao, Y. Su, W. Chen, J. Peng and Z. Jiang, J. Memb. Sci., 2012, 415-416, 824-834.

6 S. Kang, A. Asatekin, A. M. Mayes and M. Elimelech, J. Memb. Sci., 2007, 296, 42-50.

7 X. X. Xu, C. L. Zhou, B. R. Zeng, H. P. Xia, W. G. Lan and X. M. He, Sep. Purif. Technol., 2012, 96, 229-236.

8 S.-H. Oh, J.-W. Ma, J. M. Bae, Y. Kang, J.-P. Ahn, H.-K. Kang, J. Chae, D. Suh, W. Song, S. Kim and M.-H. Cho, Appl. Surf. Sci., 2017, 419, 1-8.

9 Z. Xu, K. Miyazaki and T. Hori, Appl. Surf. Sci., 2016, 370, 243-251. 
10 I. Gancarz, M. Bryjak, J. Wolska, A. Siekierka and W. Kujawski, Chem. Pap., 2016, 70, 350-355.

11 M. Tsuchida and Z. Osawa, Colloid Polym. Sci., 1994, 272, 770-776.

12 I. Punga and G. Borcia, J. Adv. Res. Phys., 2013, 4, 1-5.

13 J. G. A. Terlingen, H. F. C. Gerritsen, A. S. Hoffman and J. Feijen, J. Appl. Polym. Sci., 1995, 57, 969-982.

14 K. Y. Wang, S. W. Foo and T. S. Chung, Ind. Eng. Chem. Res., 2009, 48, 4474-4483.

15 W. Chen, Y. Su, J. Peng, X. Zhao, Z. Jiang, Y. Dong, Y. Zhang, Y. Liang and J. Liu, Environ. Sci. Technol., 2011, 45, 65456552.

16 A. K. Manna, M. Sen, A. R. Martin and P. Pal, Environ. Pollut., 2010, 158, 805-811.

17 M. Amirilargani, A. Sabetghadam and T. Mohammadi, Polym. Adv. Technol., 2012, 23, 398-407.

18 B. P. Tripathi, N. C. Dubey, R. Subair, S. Choudhury, M. Stamm, K. T. Gause, J. J. Richardson, F. Caruso and V. Abetz, RSC Adv., 2016, 6, 4448-4457.

19 R. M. Elkhaldi, S. Guclu and I. Koyuncu, Desalin. Water Treat., 2016, 57, 26003-26013.

20 O. Jirsak, F. Sanetrnik, D. Lukas, V. Kotek, L. Martinova and J. Chaloupek, WO Pat., WO/2005/024101, 2005.

21 K. Smolinska, M. Bryjak, J. Wolska and W. Kujawski, Mater. Chem. Phys., 2014, 148, 548-553.

22 K. Smolinska and M. Bryjak, Desalination, 2012, 300, 64-69. 23 M. Ulbricht and G. Belfort, J. Memb. Sci., 1996, 111, 193-215.

24 D. S. Wavhal and E. R. Fisher, J. Memb. Sci., 2002, 209, 255269.

25 M. Suzuki, A. Kishida, H. Iwata and Y. Ikada, Macromolecules, 1986, 19, 1804-1808.

26 M. Gorjanc, M. Mozetič, G. Primc, A. Vesel, K. Spasić, N. Puač, Z. L. Petrović and M. Kert, Appl. Surf. Sci., 2017, 419, 224-234.

27 Y. Fatma, A. Siekierka, M. Bryjak and J. Maryska, IOP Conf. Ser.: Mater. Sci. Eng., 2017, 254, 102011.

28 F. Yalcinkaya, B. Yalcinkaya, J. Hruza and P. Hrabak, Sci. Adv. Mater., 2017, 9, 747-757.

29 T. D. Tran, S. Mori and M. Suzuki, Thin Solid Films, 2007, 515, 4148-4152.

30 D. M. Correia, C. Ribeiro, V. Sencadas, G. Botelho, S. A. C. Carabineiro, J. L. G. Ribelles and S. LancerosMéndez, Prog. Org. Coatings, 2015, 85, 151-158.

31 M. D. Duca, C. L. Plosceanu and T. Pop, Polym. Degrad. Stab., 1998, 61, 65-72.

32 J. Li, S. Su, L. Zhou, V. Kundrát, A. M. Abbot, F. Mushtaq, D. Ouyang, D. James, D. Roberts and H. Ye, J. Appl. Phys., 2013, 113, 24313.

33 S. N. M. Salleh, M. Z. Abdullah and A. A. Wahab, MATEC Web Conf., 2014, 13, 4014.

34 E.-G. Schlosser, Angew. Chemie, 1987, 99, 284.

35 N. Naresh Kumar, S. Yap, F. bt Samsudin, M. Khan and R. Pattela Srinivasa, Polymers, 2016, 8, 295.
36 H. Bai, X. Wang, Y. Zhou and L. Zhang, Prog. Nat. Sci.: Mater. Int., 2012, 22, 250-257.

37 R. Li, C. Chen, J. Li, L. Xu, G. Xiao, D. Yan, B. Liu, G. M. Veith, S. Dai, Q. H. Yang, H. M. Ning, J. H. Li, Y. Li and Y. H. Zhao, J. Mater. Chem. A, 2014, 2, 3057.

38 D. Mandal, K. Henkel and D. Schmeisser, J. Phys. Chem. B, 2011, 115, 10567-10569.

39 F. Yalcinkaya, B. Yalcinkaya, A. Pazourek, J. Mullerova, M. Stuchlik and J. Maryska, Int. J. Polym. Sci., 2016, 2016, 4671658.

40 B. Yan and B. Zhang, Analytical methods in combinatorial chemistry, CRC Press, 2011.

41 R. Bodîrlău, R. Bodîrlău and C. A. Teacă, Rom. J. Phys., 2008, 93-104.

42 G. E. Dunn and R. S. McDonald, Can. J. Chem., 1969, 47, 4577-4588.

43 V. N. Rai, C. Mukherjee and B. Jain, Indian J. Pure Appl. Math., 2017, 55, 775-785.

44 G. C. Nille, V. K. Singh and K. R. C. Reddy, J. Ayurveda Holist. Med., 2016, 4, 1-11.

45 A. Bashir, S. K. Raghuvanshi, S. Hartha, N. P. Sharma, J. B. M. Krishna and M. A. Wahab, Prog. Nanotechnol. Nanomater., 2013, 2, 42-46.

46 B. S. Gupta, B. P. Jelle, T. Gao and T. Gao, Int. J. Spectrosc., 2015, 2015, 1-7.

47 M. Bryjak, H. Hodge and B. Dach, Appl. Macromol. Chem. Phys., 1998, 260, 25-29.

48 W. Zhang, Z. Shi, F. Zhang, X. Liu, J. Jin and L. Jiang, Adv. Mater., 2013, 25, 2071-2076.

49 J. Kong and K. Li, Sep. Purif. Technol., 1999, 16, 83-93.

50 Z. Zhou and X.-F. Wu, Mater. Lett., 2015, 160, 423-427.

51 M. Obaid, H. O. Mohamed, A. S. Yasin, M. A. Yassin, O. A. Fadali, H. Kim and N. A. M. Barakat, Water Res., 2017, 123, 524-535.

52 W. Zhang, Y. Zhu, X. Liu, D. Wang, J. Li, L. Jiang and J. Jin, Angew. Chem., Int. Ed., 2014, 53, 856-860.

53 F. Zhang, S. Gao, Y. Zhu and J. Jin, J. Memb. Sci., 2016, 513, 67-73.

54 C. Yang, G. Zhang, N. Xu and J. Shi, J. Memb. Sci., 1998, 142, 235-243.

55 X. Hu, Y. Yu, J. Zhou, Y. Wang, J. Liang, X. Zhang, Q. Chang and L. Song, J. Memb. Sci., 2015, 476, 200-204.

56 M. H. Tai, P. Gao, B. Y. L. Tan, D. D. Sun and J. O. Leckie, ACS Appl. Mater. Interfaces, 2014, 6, 9393-9401.

57 C.-T. Hsieh, J.-P. Hsu, H.-H. Hsu, W.-H. Lin and R.-S. Juang, Surf. Coat. Technol., 2016, 286, 148-154.

58 C. Li, C. Song, P. Tao, M. Sun, Z. Pan, T. Wang and M. Shao, Sep. Purif. Technol., 2016, 168, 47-56.

59 M.-C. Yang and J.-H. Tong, J. Memb. Sci., 1997, 132, 63-71.

60 I.-C. Kim, H.-G. Yun and K.-H. Lee, J. Memb. Sci., 2002, 199, 75-84. 